\title{
The Use of Dashboards in Performance Management: Evidence from Sales Managers
}

Oana Velcu-Laitinen. Aalto University. Finland oana.velcu@ aalto.fi

Ogan M. Yigitbasioglu. Queensland University of Technology. Australia ogan.yigitbasioglu@qut.edu.au

\begin{abstract}
The purpose of this paper is to identify and empirically examine the key features, purposes, uses, and benefits of performance dashboards. We find that only about a quarter of the sales managers surveyed in Finland used a dashboard, which was lower than previously reported. Dashboards were used for four distinct purposes: (i) monitoring, (ii) problem solving, (iii) rationalizing, and (iv) communication and consistency. There was a high correlation between the different uses of dashboards and user productivity indicating that dashboards were perceived as effective tools in performance management, not just for monitoring one's own performance but for other purposes including communication. The quality of the data in dashboards did not seem to be a concern (except for completeness) but it was a critical driver regarding its use. This is the first empirical study on performance dashboards in terms of adoption rates, key features, and benefits. The study highlights the research potential and benefits of dashboards, which could be valuable for future researchers and practitioners.
\end{abstract}

Keywords: Dashboards, Performance Measurement, Performance Management, Presentation Format, Display Format, Visualization, Graphs

\section{INTRODUCTION}

Dashboards are diagnostic tools designed to provide busy managers with a quick overview of a company's performance. As a concept, performance dashboards have been around for many years and reports indicate that they have been widely

The authors have received funding from Tekes (The Finnish Funding Agency for Technology and Innovation) for the research and authorship of this article. 
adopted by businesses. For example, already a 2004 survey by The Data Warehousing Institute reported that about half of the 473 business intelligence professionals were using dashboards and that a further $17 \%$ of the respondents were in the process of developing a dashboard solution in their organizations (Eckerson, 2006). Also, a more recent survey by Gartner Inc. found that dashboards have been rapidly replacing reporting and ad-hoc analysis in Western organizations (Sallam, 2011).

It is therefore not surprising that to date many textbooks have been written on dashboards (e.g. Few, 2006, Rasmussen et al., 2009). This literature is mainly concerned with the technical design aspects of dashboards. However, very little is known about actual dashboard implementations, i.e. how they are utilized and whether they have been effective in organizations. So far, the only evidence on dashboard benefits comes from the business press which report on improvements on for example, accounts receivable and budgeting (see Miller and Chioffi 2004; Kawamoto and Mathers, 2007).

As far as scientific publications are concerned, the few available studies on dashboards have looked at their motivation (Wind, 2005; Pauwels et al. 2009), implementation or implementation stages (Muntean et al. 2011; Pauwels et al. 2009), selection of metrics (DeBusk et al., 2003, Pauwels et al. 2009) and their design (Yigitbasioglu and Velcu, 2012). Hence, as previous research points out (Pauwels et al., 2009; Yigitbasioglu and Velcu, 2012), there is a lack of knowledge regarding dashboard experiences, which is the motivation for this study.

This study reports on the results of a survey with sales managers regarding the use of dashboards in Finnish companies. According to the results, only about a quarter of the respondents used a dashboard, which was much lower than expected. Sales managers used dashboards for four distinct purposes (monitoring, problem solving, rationalizing, communication and consistency).

Furthermore, there was a high correlation between dashboard uses and user productivity indicating that dashboards were perceived as effective tools in performance management, not just for monitoring one's own (department's) performance but for other purposes such as decision rationalization and communication. The quality of the data in dashboards was not a concern but, as expected, it was a critical driver for its use. 


\section{PERFORMANCE DASHBOARDS}

Dashboards are a particular type of Decision Support Systems (Arnott and Pervan, 2005) and can be defined as "a visual and interactive performance management tool that displays on a single screen the most important information needed to achieve one or several individual and/or organizational goals, allowing the user to identify, explore, and communicate problem areas that need corrective action" (Yigitbasioglu and Velcu, 2012, p. 4).

Dashboards incorporate visual and functional features, which in combination help improve cognition and interpretation (Yigitbasioglu and Velcu, 2012). They may be used by different users such as front-line workers to monitor inventory, by middle managers to analyze lagging measures, and by executive managers to evaluate strategic performance against objectives.

Various factors have played an important role in the development of dashboards: firstly, the advancements in IT that provided the technical infrastructure to build them relatively efficiently on the business intelligence layer. Secondly, the introduction of new techniques in performance measurement such as the Balanced Scorecard (Kaplan and Norton, 1992) highlighted the importance of multidimensional performance measurement. Finally, the need for cross-department integration in performance reporting, as well as managerial bias in information processing are considered to be some of the most important factors driving dashboard adoption (LaPointe, 2005).

In more recent years, dashboards have evolved from the intrinsic purpose of monitoring performance to more advanced analytical purposes, incorporating new features such as (i) scenario analysis, (ii) drill down capabilities, (iii) and presentation format flexibility (e.g. tables or graphs). Given the rapid developments in business technologies, the future is likely to bring additional novelties to dashboards such as their integration with work flow management systems (Yigitbasioglu and Velcu, 2012).

Dashboards draw on theories from a variety of disciplines including information systems, accounting, and cognitive psychology. They communicate complex data to the decision maker through a process called visualization. Visualization refers to interactive visual representations of abstract, nonphysically based data to amplify cognition (Card et al. 1999). The motivation for 
using visualization in dashboards can probably be best explained through cognitive fit theory. Cognitive fit theory focuses on the fit between an individual's decision-making skills, the information presentation format and the task at hand, providing useful guidelines with regard to the choice of presentation format to be applied. For example, graphs are well suited for spatial tasks that involve forecasting and comparisons as well as for tasks that require multidimensional data analysis and pattern recognition. On the other hand, tabular information is more appropriate for symbolic tasks and for users who are more numerical (e.g. accountants and financial analysts) (Vessey and Galletta, 1991).

Cognitive fit theory postulates that decisions made under the fit condition are superior compared to the non-fit. Since tasks related to performance monitoring involve comparisons of a variety of measures (Key Performance Indicators), the presentation of information in graphical format is well justified. Nevertheless, because of the diversity of dashboard users' knowledge, skills, and cognitive profiles, it is recommended that dashboards come with some level of flexibility in terms of drill down capabilities and presentation format flexibility (Yigitbasioglu and Velcu, 2012).

Similarly, the task-technology fit theory focuses on the fit between individual abilities, task requirements, and the functionality of the technology (Goodhue and Thompson, 1995). For example, certain kinds of tasks that require information from different organizational units require technological functionality under the form of integrated databases throughout an organization. Thus dashboards need to be designed in the light of the tasks and users that it is required to support.

\subsection{Different Purposes of Dashboards}

Pauwels et al. (2009) suggest four possible purposes of using dashboards: (i) monitoring, (ii), consistency (iii) planning, and (iv) communication. Monitoring refers to the day to day evaluation of metrics that should result in corrective action. Monitoring could be considered as the dashboard's most fundamental function. Consistency relates to the alignment of measures and measurement procedures used across departments and business units. Dashboards may also be used for planning given that scenario analysis is present among its features. Finally, a dashboard communicates both performance and the values of an organization to its stakeholders through the choice of the metrics. Some of the 
above mentioned purposes were confirmed in surveys conducted by professional organizations (Clark et al., 2006).

Valuable insight with regard to the use of dashboards can also be drawn from the information systems literature. For example, Doll and Torkzadeh (1998) measured how intensively employees used management information systems (MIS) to perform their jobs in terms of (i) problem solving, (ii) work integration, and (iii) customer service. Building on Doll and Torkzadeh (1998), Wiersma (2009) identified three purposes regarding the use of the BSC, which may be applicable to the context of dashboards. The purposes were identified as (i) decision-making and decision-rationalizing; (ii) communication and consistency, and (iii) self-monitoring, which agree with Pauwels et al. (2009). Decisionmaking and decision-rationalizing refer to the opportunity that managers see in using the dashboard to enable them to extract any relevant information which they can base their decisions on and whether they can rationalize the decisions to themselves or their superiors. The self-monitoring, communication and consistency purposes relate to the dashboard's characteristic of displaying the status of the work in process and making it visible to the employees who are process owners or who are responsible for the process. When integrated with enterprise systems, dashboards enable different stakeholders in the same work process to visualize the same information. The respective users may see this as an opportunity to monitor their own performance in real-time and to coordinate the actions with other managers in the process, while subordinates may see it as an opportunity to communicate vertically the performance of their work. Hence, we pose the following research question.

RQ1: With what intensity and purposes do managers use dashboards and how does this affect user productivity?

\subsection{Dashboard Key Functional Features}

During the past years, software vendors such as Business Objects, Cognos, QlikView, Microsoft, and JasperSoft, competed in developing cutting edge dashboard solutions. Although, vendors claim that the use of dashboards enhance organizational performance in terms of improved customer satisfaction, return on investment, and increase in cash flow, some companies may prefer simpler alternatives. Thus, despite the criticism as being too flat, too manual and too 
isolated, performance dashboards in the form of Excel spreadsheets are most widely used by companies (Neely et al., 2008).

Based on the reviewed literature, desired functional features of dashboards include (i) real-time notifications and alerts, (ii) drill-down capabilities, (iii) scenario analysis, (iv) presentation flexibility/theory guided format selections, and (v) external benchmarking, (Pauwels et al. 2009; Ying et al., 2009, Yigitbasioglu and Velcu 2012). Real time notifications and alerts are necessary so that corrective actions can be triggered as soon as the measures deviate from predefined targets. Alerts can be relatively easily implemented through the use of distinct colours, flashing and/or even audio signals. The drill down feature is highly desirable as it would allow users to slice and dice data for a more detailed analysis without which the users would be forced to switch to another reporting tool. The drill down feature would also benefit low analytics that might perform better with less aggregate data, as well as tasks that have a high level of uncertainty (Bariff and Lusk, 1977; Benbasat and Dexter, 1979). Scenario analysis may be a useful feature, especially when the dashboard is intended to be used as a planning tool. Thus, users can utilize it as a decision support tool to see how changes in certain variables (e.g. order fill rates) impact other variables (e.g. profits), highlighting and communicating the importance of leading variables to its users. A further feature, presentation flexibility, which is the ability to view data in different ways (e.g. tables or graphs) through point-and-click could be valuable due to the earlier discussion on cognitive fit theory. Theory guided format selection is related to the previous item (presentation flexibility) to the extent that the system decides on the most appropriate data format in the light of the task and/or user profile instead of leaving the choice to the user (Huber, 1983). Finally, external benchmarking, can give users valuable insight with respect to how well the organisation is performing in relation to its competitors.

From the above features, we identify three (key) features as the most critical: drill down, scenario analysis, and presentation flexibility. We think it is these features that make dashboards a dynamic and effective tool suitable for many types of users and tasks. Given these key features, we are led to the second research question:

RQ2: To what extent are the identified key features present in adopted dashboards and how do they affect user productivity? 


\subsection{Data Quality Issues}

Data quality refers to the quality of the information content displayed on the dashboard's screen. Data quality is an issue in dashboards according to two surveys conducted in 2001 and 2003 on large US firms (Clark et al., 2006). Quality issues with respect to data might stem from application integration problems, which might lead to avoidance of using dashboard provided data and substitution with more traditional tools (e.g. MS Excel) and reports (e.g. periodical sales report print-outs). Even in cases when there is no objective quality issue related to the dashboard data, it may be an issue of managerial preference to use other sources of data.

In the IS literature, the definition of data quality refers to both the content and the format of data which is produced by information systems (Gorla et al., 2010). Huh et al. (1990) and Nelson et al. (2005) define quality not in an objective sense, but rather in terms of the perceptions of data consumers who are working on specific tasks and within specific contexts. In this paper, we adopt the same point of view based mainly on the belief that it is not only important for the data to have high quality but it is equally important for the data to be perceived to have high quality. Huh et al. (1990) used the constructs of accuracy, completeness, currency and consistency for data quality. Data is accurate when not only it is correct, unambiguous, and objective but also meaningful and believable. Data is complete depending on the demands of users. Therefore, for some users data may fulfil all the requirements to perform their tasks, whereas for other users data can be incomplete. Currency refers to up-to-date data and considering that different users have different needs of up-to-date information. Data currency is dependent on task and user perception. Consistency refers to the absence of conflicts between two datasets and to the believability of the data produced by the system during a longer period of user experience.

In organizations, decision-makers most often work under time pressure to reach multiple objectives. Previous research showed that under time pressure, managers may prefer to use sources of information that provide better accessibility to information but who might have a low perception of its quality in terms of accuracy, reliability, and timeliness (Reilly, 1982). This might be the case here, as one of the benefits of dashboard implementations is the fast accessibility to information, which refers to the degree to which the dashboard 
and the information it contains can be accessed with relatively low effort (Nelson et al., 2005, Pauwels et al., 2009). This leads to our final research question:

RQ3: How do users perceive the quality of data in dashboards and how does it affect its use?

\section{THE SURVEY AND SAMPLE SELECTION}

The survey instrument made strong use of pretested measures and included at least three items for each construct to improve construct validity. The items were measured on a 1-7 Likert scale (strongly disagree, 7 strongly agree). Dashboard purposes and use were based on Doll and Torkzadeh (1998), which were also adopted in Wiersma (2009) in the context of BSC usage. We changed the wording to reflect dashboard use instead of system or BSC use. Perceived data quality was measured in terms of data accuracy, reliability, completeness, and timeliness, which was consistent with Huh et al. (1990) and Reilly (1982). We also measured control tightness, i.e. results, action, personnel, and cultural controls to see if they were able to explain dashboard adoption. These were adopted from Wiersma (2009). A complete list of all the constructs with the corresponding questions can be found in Appendix 1.

The sample for the survey was obtained from the Fonecta ProfinderB2B database, which includes financial figures and contact details of companies in Finland. The search was not limited to any particular industry. However, we targeted companies with a turnover of at least 1 million EUR regarding the 2010 Financial Year. The number of employees in the search was set to at least 50. The query returned 941 companies. The target respondents for the survey were high level sales managers with the titles "Sales Manager" or "Sales Vice President". Sales managers were the target group because they were expected to be one of the user groups that use most frequently the dashboard solutions (Eckerson, 2006). Emails were sent to the companies at the end of 2010 including a cover letter and the link to the online survey. Ninety e-mails were returned as undelivered, which brought down the sample size to 851 . Reminders were sent twice and the total number of responses was 145 . This corresponds to a response rate of $17 \%$. The response rate was influenced by the time of the survey (between Christmas and the New Year) and the senior levels of managers in the target group. Out of the 145 that responded to the survey, only 36 indicated the use of a dashboard, including 7 that developed the dashboard in Excel. From the remaining 109 non- 
users, 62 indicated the use of "other reporting tools that make the implementation of a dashboard obsolete". The rate of adoption was about a quarter of the companies in the sample. Out of the 145 responses, 120 were received from Sales Vice Presidents and the remaining 25 from Sales Managers.

\section{DESCRIPTIVE STATISTICS}

The following three figures present comparative statistics regarding industry, turnover and, employee size for dashboard users and the entire sample.

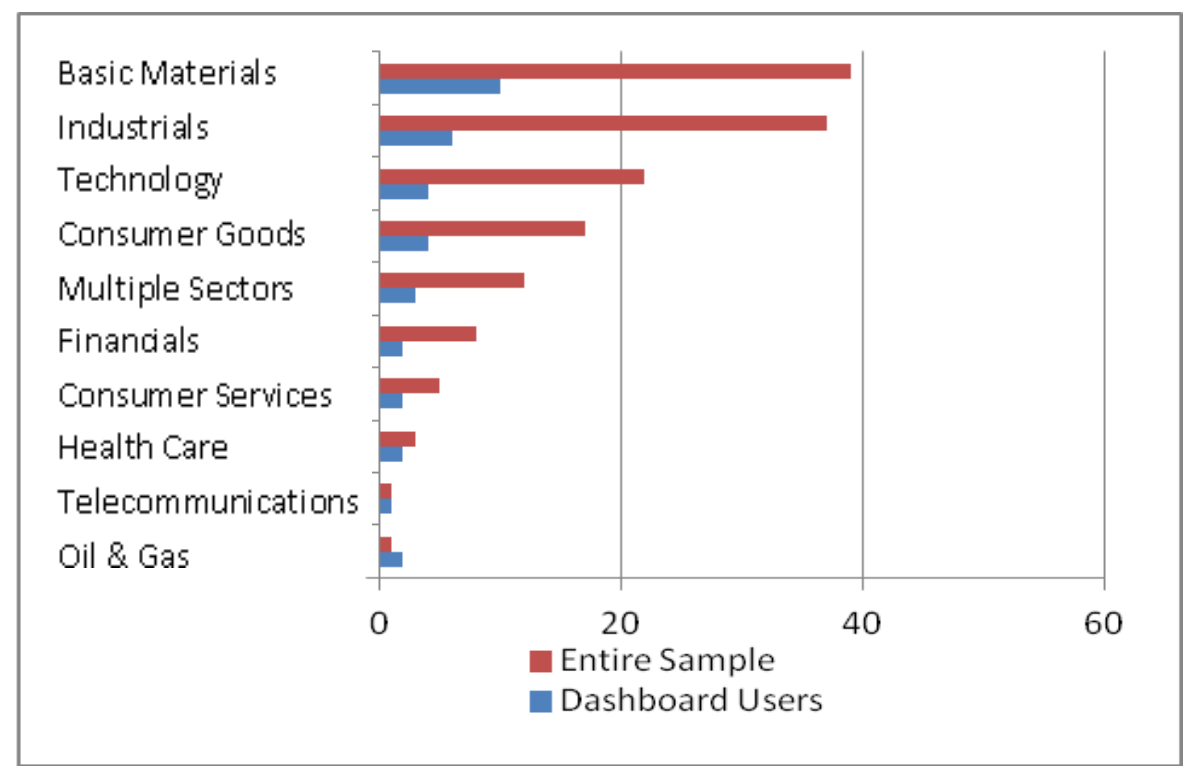

Figure 1 Industry

A wide range of industries were represented. Industry classifications followed the Industry Classification Benchmark used by Dow Jones and FTSE (Figure 1). Basic Materials, Industrials, and Technology sectors led the sample, which also included service companies such as transportation companies and IT service providers. Manufacturing and service companies had about an equal share. Although, the entire sample represented companies of all sizes, over half of the dashboard users tended to be in the relatively larger turnover categories of 200 million EUR or more (Figure 2). Furthermore, more than two thirds of the companies in the entire sample had employees of 499 or less (Figure 3). There was no indication that companies with more employees utilized dashboards more compared to companies with fewer employees. 


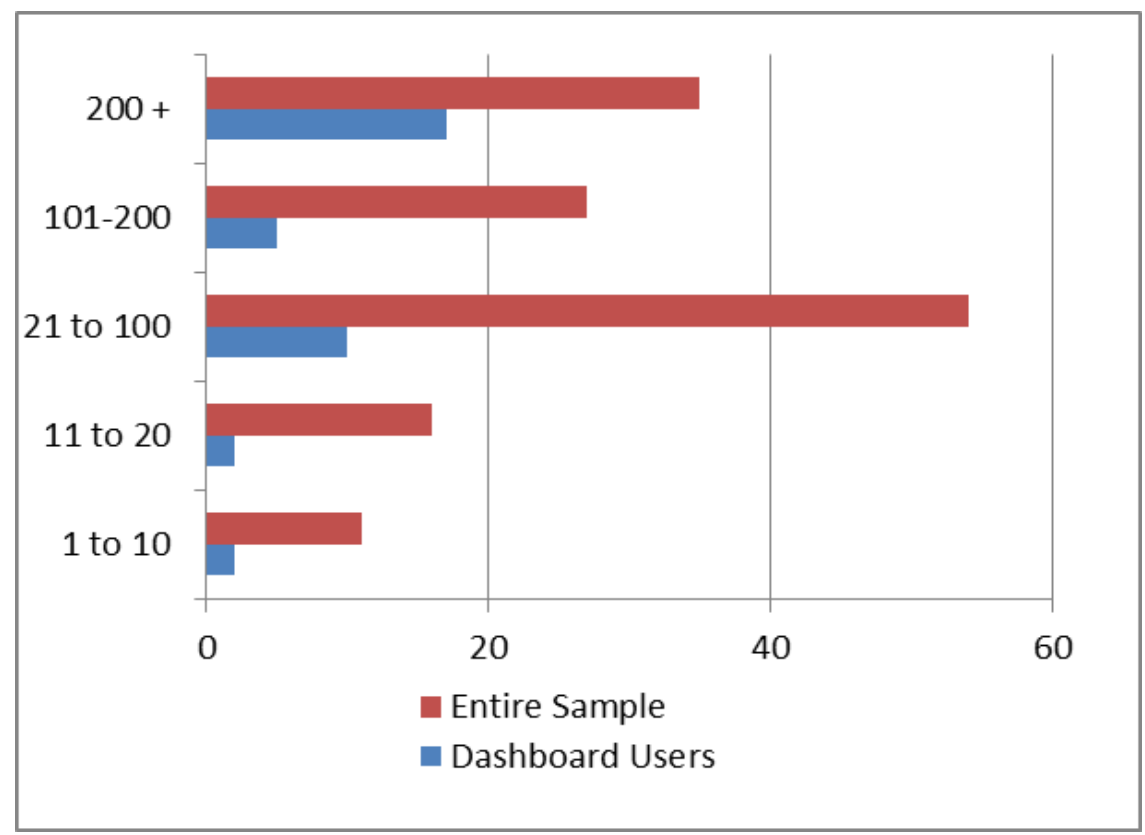

Figure 2 Turnover in million EUR

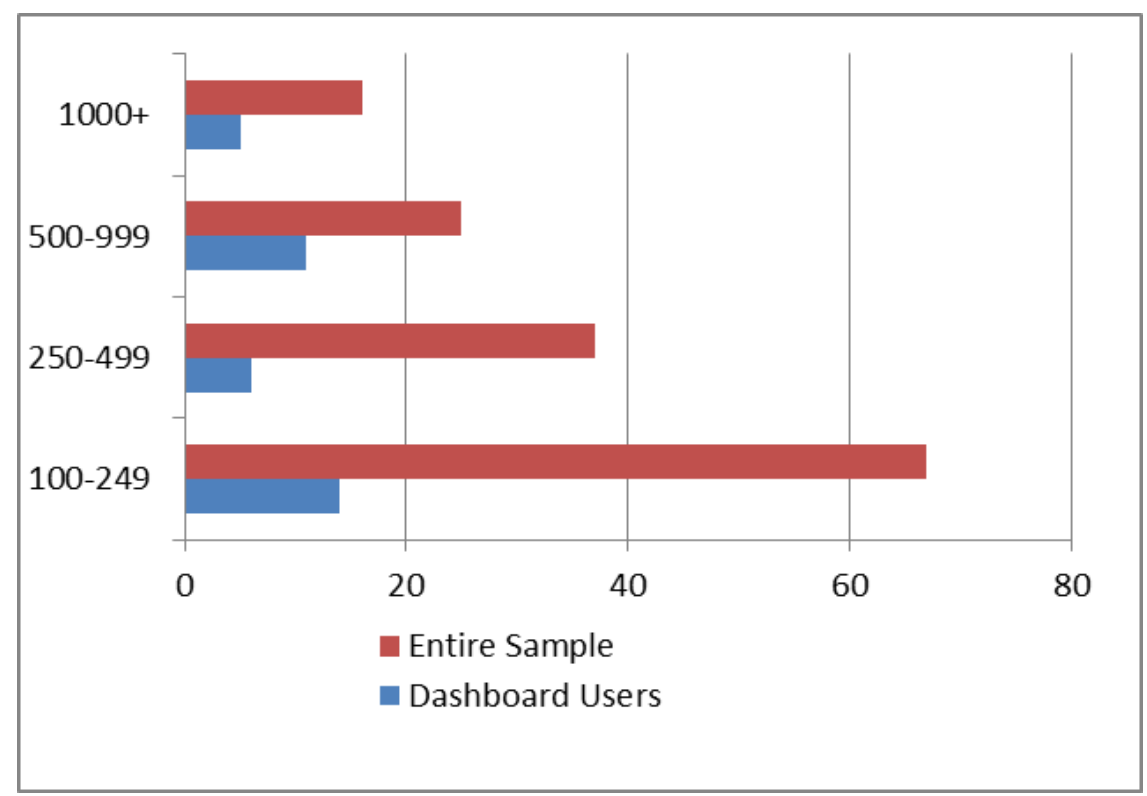

Figure 3 Number of Employees

\section{RESULTS}

Internal consistency of the measures was checked using factor analysis and by observing the values for Cronbach's alpha. One question regarding the completeness of data from the data quality measure was taken out due to low 
loading. Internal consistency values for the control tightness constructs (results control, action control, etc.) were not satisfactory as they were below the desired 0.7 threshold for Cronbach's alpha. All the other measures had satisfactory values, mostly above 0.8 .

In terms of the features of the dashboards, the means of the relevant measures provide some insight (Table 1). The drill down feature received the highest score followed by presentation flexibility and scenario analysis. Dashboards were used for all the four purposes, whereby communication, consistency, and monitoring ranked the highest (Table 2). The mean value for data quality was 5.48 on a scale from 1-7.

\begin{tabular}{lrr}
\hline Measure & Mean & Standard Deviation \\
\hline Drill Down & 4.5069 & 1.38291 \\
Presentation Flexibility & 4.1204 & 1.40329 \\
Scenario Analysis & 4.0926 & 1.38154 \\
\hline
\end{tabular}

Table 1: Mean values of dashboard features (Scale 1-7)

\begin{tabular}{lrr}
\hline Measure & Mean & Standard Deviation \\
\hline ComCon & 5.2778 & .91569 \\
Monitoring & 5.1481 & 1.29086 \\
Ration & 5.0389 & 1.17285 \\
ProbSol & 4.8056 & 1.09725 \\
\hline
\end{tabular}

Table 2: Mean values of dashboard purposes (Scale 1-7)

Two-tailed Pearson's correlation analysis results $(\mathrm{N}=36)$ are presented in Table 3. There were positive correlations between dashboard use dimensions (problem solving, rationalization, communication, etc.) and user productivity, which were all highly significant (RQ1). Dashboard features in terms of drill down and scenario analysis were also positively correlated with productivity (RQ2). However, presentation flexibility was not significantly correlated with productivity. Finally, data quality had positive and significant correlations with dashboard uses (RQ3). Correlations for problem solving and rationalization were especially high. Independent-samples t-tests between the adopters and nonadopters showed a significant difference for the results control variable, which measured the emphasis placed upon performance measurement. 


\begin{tabular}{|c|c|c|c|c|c|c|c|c|c|}
\hline & \multirow{2}{*}{$\begin{array}{c}\text { Qual. } \\
\text { DQ }\end{array}$} & \multicolumn{3}{|c|}{ Dashboard Features } & \multicolumn{4}{|c|}{ Dashboard Use and Purposes } & \multirow{2}{*}{$\begin{array}{c}\text { Prod. } \\
\text { Prod }\end{array}$} \\
\hline & & PrFlx & Drill & Scen. & PrbSol & Ration & ComC & Monit & \\
\hline DQ & 1 & & & & & & & & \\
\hline PrFlx. & $.517^{* *}$ & 1 & & & & & & & \\
\hline Drill & $.537^{* *}$ & $.469^{* *}$ & 1 & & & & & & \\
\hline Scen & .245 & .264 & $.583^{* *}$ & 1 & & & & & \\
\hline PrbSol & $.638^{* *}$ & $.306^{*}$ & $.332^{*}$ & $.304^{*}$ & 1 & & & & \\
\hline Ration & $.606^{* *}$ & .249 & $.380^{*}$ & $.328^{*}$ & $.872^{* *}$ & 1 & & & \\
\hline ComC & $.421^{*}$ & .249 & $.357^{*}$ & $.414^{*}$ & $.718^{* *}$ & $.664^{* *}$ & 1 & & \\
\hline Monit & $.318^{*}$ & .127 & $.466^{* *}$ & $.412^{*}$ & $.424^{* *}$ & $.532^{* *}$ & $.423^{*}$ & 1 & \\
\hline Prod & $.421^{*}$ & .315 & $.569^{* *}$ & $.619^{* *}$ & $.644^{* *}$ & $.744^{* *}$ & $.700^{* *}$ & $.693^{* *}$ & 1 \\
\hline
\end{tabular}

Table 3: Correlation coefficients

\section{DISCUSSION AND CONCLUSIONS}

This explorative study found evidence for the multifaceted use of dashboards in performance management (RQ1). Dashboards are most intensively used for communication and consistency purposes, even more than for self-monitoring. This highlights the fact that dashboards are to be seen as collaborative tools rather than individual decision support systems that help communicate the values and objectives of the company as much as what has to be fixed to achieve them. These results also confirm the dashboard purposes as put forward by Pauwels et al. (2009). Furthermore, the results provide evidence with respect to dashboard benefits (RQ1), which so far lacked support to a large extent. Thus, improved performance monitoring, decision rationalization, communication, and problem solving can enhance and speed up the decision making process, leading to more informed decisions that are less likely to be resisted by others.

In terms of the key features available in dashboards (RQ2), the drill down feature scored the highest, although the high standard deviation suggests that many dashboards lack this important feature. The other two features (presentation flexibility and scenario analysis) were less common. Thus, the results imply that dashboards that are adopted by organizations were nowhere near the ideal reporting tools that we envisaged.

As far as the associations between the key features and user productivity are concerned (RQ2), data suggests that there are positive relationships between the drill down and scenario analysis features and productivity, indicating that these 
features are highly valuable to decision makers. Surprisingly, presentation flexibility did not seem to impact productivity, which might mean that they did not see this feature as important but perhaps more as 'nice to have'. Hence, companies planning to adopt dashboards should consider including at least the drill down and scenario analysis features to take full advantage of this technology.

The quality of the data in the dashboards did not seem to be an issue, although there were concerns regarding the completeness of the data (as evidenced by the low loading) (RQ3). This could suggest that companies might be facing application integration problems, which has been widely reported in the IS literature (e.g. March and Hevner, 2007). Nevertheless, data quality is a prerequisite for dashboards' success, which can drive or inhibit their use (RQ3).

This study found that only a quarter of the sales managers in the sample used a dashboard, which was much lower than figures reported by the business press. The low adoption rate was also surprising given that Finland is in the top 3 on the worldwide rank of the impact of IT on its development and national competitiveness (Dutta and Mia, 2011). The reason for this finding might be the target group. Whereas we targeted sales managers, previous surveys focused on business intelligence professionals who are the pioneers in this field. Thus, it might be taking some time for the new tools to be embraced by senior employees who are not as technologically savvy as employees in other functions. On the other hand, 62 out of the 109 non-dashboard users indicated that they were using other reporting tools, which makes the adoption of dashboards unnecessary. This could indicate that many companies rank low on BI maturity (Muntean et al., 2011 for BI maturity levels). Furthermore, users of dashboards tended to be in organizations with a relatively high turnover (more than 200 million EUR), which could suggest that dashboard adoption, as with other technologies, is likely to be subject to the financial resources of companies.

Companies have been heavily investing into IT since the late 90's and they may have become reluctant to constantly spend resources on new tools that they may not perceive as significantly novel to justify investment. However, we are in the view that dashboards fill a critical gap in reporting and that companies might be forgoing an opportunity to better leverage existing IT and business intelligence infrastructure. We also think that dashboards could bring together many of the performance management and IT related concepts such as the BSC, Strategy 
Maps, business intelligence etc., offering users a 'one stop-shop' for all performance and strategy related information. This would significantly reduce the information load problem by decreasing the number of tools that the management is required to use nowadays.

Overall, this study contributes to the accounting and information system literature by providing evidence on the adoption rates, uses, and benefits of dashboards, a field that has so far been clearly neglected. Researchers and practitioners might find this study valuable as it highlights the potential of a relatively new research area and because it provides evidence for dashboard's business value. Given the rapid growth of data (and reporting needs) in companies as a consequence of the adoption of new promising tools such as data mining and continuous auditing (Vasarhelyi and Halper 1991), we expect the field of dashboards to be highly relevant in the future.

\subsection{Limitations and Future Research}

The main limitation of the study relates to the sample size, which was small due to firstly, the fact that most of the responses we received were from non-dashboard users and secondly, the low response rate. Therefore, we were limited with respect to the statistical techniques we applied to analyse the data. Nevertheless, we were able to draw some interesting conclusions. However, we acknowledge the limitation with respect to generalizability. Another limitation relates to our intention of keeping the survey short as it targeted senior level employees. Thus, we did not for example attempt to capture all of the possible features (e.g. visual features) of the dashboards used by organizations. Thirdly, some of the measures, i.e. those relating to control tightness did not perform well and would have to be refined in future studies.

Despite their popularity, empirical research on performance dashboards is almost nonexistent. This paper shows that the area of dashboards is a promising research field, which is part of the broader research stream of Decision Support Systems. Future research should continue focusing on the business value of dashboards in performance management. Studies with larger or targeted sample sizes and with more refined measures, as well as data from other geographical regions would help improve external validity and theory. Larger data sets would also allow comparisons between various sectors as IT support and business intelligence requirements may differ across industries. Much needed are also case 
studies of successful or unsuccessful dashboard implementations which can provide value in terms of identifying the critical success factors.

\section{REFERENCES}

ARNOTT, D.; PERVAN, G.; (2005): “A critical analysis of decision support systems research", Journal of Information Technology, vol. 20: 67-87. http://dx.doi.org/10.1057/palgrave.jit.2000035

BARIFF, M.L, LUSK, E.J. (1977): "Cognitive and Personality Tests for the Design of Management Information Systems", Management Science, vol. 23, n. 8: 820-829. http://dx.doi.org/10.1287/mnsc.23.8.820

BENBASAT I, DEXTER A.S. (1979): "Value and events approaches to accounting: an experimental evaluation", Accounting Review, vol. 54, n. 4: 735749 .

CARD, S.K.; MACKINLAY, J.D.; SCHNEIDERMAN, B. (1999): Readings in Information Visualization: Using Vision to Think, Morgan Kaufmann; 1st edition.

CLARK, B.H.; ABELA A.V.; AMBLER T.; (2006): "Behind the wheel", Marketing Management, vol. 15, n. 3: 18-23.

DEBUSK G.K.; BROWN, R.M.; KILLOUGH, L.N. (2003): “Components and relative weights in utilization of dashboard measurement systems like the Balanced Scorecard", The British Accounting Review vol. 35, n. 3: 214-231. http://dx.doi.org/10.1016/S0890-8389(03)00026-X

DOLL, W.J.; TORKZADEH G. (1998): "Developing a multi-dimensional measure of system-use in organizational context", Information \& Management, vol. 33, n. 4: 171-185. http://dx.doi.org/10.1016/S0378-7206(98)00028-7

DUTTA, S.; MIA I. (2011): “The Global Information Technology Report 20102011, Transformations 2.0", available at http: //reports.weforum.org/globalinformation-technology-report/ (accessed 21 December 2011):

ECKERSON, W.W. (2006): Performance Dashboards: Measuring, Monitoring and Managing Your Business, John Wiley \& Sons, Inc.; Hoboken, New Jersey.

FEW, S. (2006) Information Dashboard Design, The Effective Visual Communication of Data, O'Reilly Media, Inc, First Edition 2006.

GOODHUE, D.L.; THOMPSON R.L. (1995): "Task-Technology Fit and Individual Performance”, MIS Quarterly, vol. 19, n. 2: 213-236. http://dx.doi.org/ $\underline{10.2307 / 249689}$ 
GORLA, N, SOMERS T.M.; WONG, B. (2010): "Organizational impact of system quality, information quality and service quality", Journal of Strategic Information Systems, vol 19, n. 3: 207-228. http://dx.doi.org/10.1016/j.jsis.2010.0 $\underline{5.001}$

HUBER, G. P. (1983): "Cognitive style as a basis for MIS and DSS designs: Much ado about nothing?" Management Science, vol. 29, n. 5: 567-579. http://dx.doi.org/10.1287/mnsc.29.5.567

HUH, Y.; KELLER, F.R.; REDMAN, T.C.; WATKINS, A.R. (1990): "Data quality" Information and Software Technology, Vol. 32, n. 8: 559-565. http://dx.doi.org/10.1016/0950-5849(90)90146-I

KAPLAN, R.S.; NORTON D.P. (1992): “The balanced scorecard: Measures that drive performance" Harvard Business Review, vol. 70, n. 1: 71-79.

KAWAMOTO, T.; MATHERS, B. (2007): "Key Success Factors for a Performance Dashboard", DM Review: 20-21.

LAPOINTE, P. (2005): Marketing by the Dashboard Light, New York: MarketingNPV/ Association of National Advertisers.

MARCH, S.T.; HEVNER, H.R. (2007): "Integrated Decision Support Systems: A data warehousing perspective", Decision Support Systems, vol. 43, n. 3: 10311043. http://dx.doi.org/10.1016/j.dss.2005.05.029

MUNTEAN, M.; BOLOGA, A.; BOLOGA, R.; FLOREA, A. (2011): The use of multidimensional models to increase the efficiency of management support systems, International Journal of Mathematical Models and Methods in Applied Sciences, vol. 5 No 8: 1334-1344.

MILLER, A. CIOFFI, J. (2004): "Measuring Marketing Effectiveness and Value: The Unisys Marketing Dashboard", Journal of Advertising Research, vol. 44, n. 3: 237-243. http://dx.doi.org/10.1017/S0021849904040334

NEELY, A.D.; YAGHI, B.; YOUELL, N. (2008): "Enterprise Performance Management: The Global State of the Art", available at http://bit.ly/GO8Ham (accessed 27 November 2011)

NELSON R.; TODD, P. and WIXOM, B. (2005): "Antecedents of information and system quality: An empirical examination within the context of data warehousing", Journal of Management Information Systems, vol. 21, n. 4: 199235.

PAUWELS, K.; AMBLER, T.; BRUCE, H. C.; LAPOINTE, P.; REIBSTEIN D.; SKIERA, B.; WIERENGA, B.; WIESEL, T. (2009): "Dashboards as a Service: Why, What, How, and What Research Is Needed?" Journal of Service Research, vol. 12, n. 2: 175-189. http://dx.doi.org/10.1177/1094670509344213 
RASMUSSEN N.; CHEN C. Y.; BANSAL M. (2009): Business Dashboards, A Visual Catalogue for Design and Deployment, John Wiley \& Sons, Inc, Hoboke, New Jersey.

REILLY, C.A. (1982): "Variations in Decision Makers' Use of Information Sources: The Impact of Quality and Accessibility of Information", Academy of Management Journal, vol. 25, n. 4: 756-771. http://dx.doi.org/10.2307/256097

SALLAM, R.L. (2011): "BI Platform Users Survey, 2011: Customers Rate their BI Platform Functionality", available at http://bit.ly/GY3XgB, (accessed 24 May 2011).

VASARHELYI, M.A.; HALPER, F. B.; (1991): "The Continuous Audit of Online Systems", Auditing: A Journal of Practice and Theory, vol. 10, n. 1: 110-125.

VESSEY, I.; GALETTA, D. (1991): “Cognitive Fit: An Empirical Study of Information Acquisition" Information Systems Research, vol. 2, n. 1: 63-84. http://dx.doi.org/10.1287/isre.2.1.63

WIERSMA, E. (2009): "For which purposes do managers use Balanced Scorecards? An empirical study", Management Accounting Research, vol 20: 239-251. http://dx.doi.org/10.1016/j.mar.2009.06.001

WIND, Y. (2005): "Marketing as an Engine of Business Growth: A CrossFunctional Perspective", Journal of Business Research vol. 58, n. 7: 863-873. http://dx.doi.org/10.1016/j.jbusres.2004.01.002

YIGITBASIOGLU, O.M.; VELCU O. (2012): "A Review of Dashboards in Performance Management: Implications for Design and Research", International Journal of Accounting Information Systems, vol 13, n. 1: 41-59. http://dx.doi.org/ $\underline{10.1016 / \mathrm{j} . \operatorname{accinf} .2011 .08 .002}$

YING, L, LIJUN, X,; WEI, S. (2009): "Designing Supply Chain KPIs for UpperLevel Management", ITTA International Conference on Services Science, Management and Engineering, available at http://bit.ly/GY7FSA, (accessed 1 February 2011). 


\section{Appendix 1}

(Items measured on a 1-7 Likert scale, 1 strongly disagree, 7 strongly agree)

\section{Data Quality}

a. I think that the data in the dashboard is accurate.

b. I think that the data in the dashboard is reliable.

c. I think that the data in the dashboard is complete.

d. I think that the data in the dashboard is up to date.

\section{Presentation Format Flexibility}

a. The dashboard I use is highly flexible in terms of how the data is presented.

b. The dashboard I use can show data in different ways (e.g. tables or graphs).

c. I can easily change the key performance indicators (KPI's) that are of interest to me.

\section{Drill-Down Feature}

a. The dashboard allows me to extensively drill down data.

b. I often use the drill down feature of the dashboard.

c. The dashboard can show data at different granularity of time (e.g. year, quarter, months, days).

d. The dashboard can present the data from different business perspectives

\section{Scenario Analysis}

a. The dashboard I use allows me to make scenario analysis.

b. The data provided by dashboard enables me to make different forecasts about the future.

c. The use of dashboard provides more time to make better business development plans.

\section{Problem Solving}

a. I use the dashboard to decide how to best approach a problem.

b. I use the dashboard to check my thinking with the data.

c. I use the dashboard to make sense of the data.

d. I use the dashboard to analyze why problems occur. 


\section{Rationalizing}

a. I use the dashboard to help me explain my decisions.

b. I use the dashboard to help me justify my decisions.

c. I use the dashboard to help me make explicit the reasons for my decisions.

d. I use the dashboard to improve the effectiveness and efficiency of my decisions.

e. I use the dashboards to make the decisions more rational.

\section{Communication \& Consistency}

a. I use the dashboard to communicate with other people in my work group.

b. My work group uses the dashboard to coordinate our activities.

c. I use the dashboard to communicate with people who report to me.

d. I use the dashboard to communicate with people who I report to.

\section{Monitoring}

a. I use the dashboard to monitor my own performance.

b. I use the dashboard to plan my work

c. I use the dashboard to get feedback on job performance.

\section{User productivity}

a) The use of dashboard enables the understanding of the connection between my individual role and the overall business goals of the company.

b) Ever since the use of dashboard, I can get the right information in a shorter time.

c) Ever since the use of dashboard, I can perform operational tasks in less time.

d) Ever since the use of dashboard, I have more time to dedicate for the development of business.

\section{Results Control}

a. I only examine the bottom line of financial results.

b. If it was not obligatory, I would not make formal evaluation of my subordinates. reverse

c. If the results of the performance system do not meet my expectations, I adjust the performance measurement system.

d. Performance measurement is essentially superfluous in my organization. 


\section{Action Controls}

a. There are many written rules and procedures for the tasks in my organizational unit

b. The rules and procedures precisely specify how the tasks in my organization are to be done.

c. The rules and procedures are strictly enforced in my organizational unit.

\section{Degree of Personnel and Cultural control}

a. The evaluation of personnel is relatively unimportant because I trust them.

b. Employees participate to frequent training programs.

c. Training programs are voluntary.

d. By taking care of a good culture in my organizational unit, I can depend upon people doing their job as best they are able to. 